\title{
TRMM Observations of Intraseasonal Variability in Convective Regimes over the Amazon
}

\author{
Walter A. Petersen \\ Department of Atmospheric Science, Colorado State University, Fort Collins, Colorado \\ STEPHEN W. NesbitT \\ Department of Meteorology, University of Utah, Salt Lake City, Utah \\ RICHARD J. BLAKESLEE \\ NASA Marshall Space Flight Center, Huntsville, Alabama \\ Robert Cifelli, Paul Hein, and Stephen A. Rutledge \\ Department of Atmospheric Science, Colorado State University, Fort Collins, Colorado
}

(Manuscript received 22 March 2001, in final form 26 October 2001)

\begin{abstract}
This study utilizes the Tropical Rainfall Measuring Mission (TRMM) satellite precipitation radar (PR), lightning imaging sensor (LIS), and passive microwave imager (TMI) data together with ground-based lightning data to investigate the vertical structure, lightning, and rainfall characteristics of Amazonian and subtropical South American convection for three separate wet seasons. These characteristics are partitioned as a function of 850$\mathrm{mb}$ zonal wind direction, motivated by observations collected during the 6-week TRMM-Large-scale BiosphereAtmosphere Experiment in Amazonia (LBA) field campaign. The TRMM-LBA field campaign observations suggest that systematic variations in Amazonian convective vertical structure, lightning, and rainfall are all linked to bimodal variations in the low-level zonal wind (e.g., easterly and westerly regimes). The more spatially and temporally comprehensive TRMM dataset used in this study extends the TRMM-LBA observations by examining regime variability in Amazonian and South American convective structure over a continental-scale domain.

On a continental scale, patterns of east and west regime 850-700-mb winds combined with LIS lightning flash densities suggest the presence of synoptic-scale controls [e.g., intrusion of extratropical frontal systems and interaction with the South Atlantic Convergence Zone (SACZ)] on regional-scale variability in convective vertical structure. TRMM PR, TMI, and ground-based lightning data suggest that regional variability in wetseason convective structure is most evident over the southern Amazon, Mato Grosso, Altiplano, southern Brazil, and eastern coastal regions of central and southern South America. Convective vertical structure, convective rainfall rates, and lightning activity are all more pronounced during easterly (westerly) regimes over the southern Amazon and Mato Grosso (Altiplano, and southern Brazil). Importantly, when considered with case study results from TRMM-LBA, the systematic differences in convective structure that occur as a function of regime suggest that associated regime differences may exist in the vertical distribution of diabatic heating. Hence the discrimination of convective vertical structure "regimes" over parts of the Amazon and vicinity based on a resolved variable such as the $850-700$-mb zonal wind direction, while far from being perfect, may have important applications to the problems of cumulus parameterization, rainfall estimation, and retrievals of latent heating over the Amazon.
\end{abstract}

\section{Introduction}

Copious amounts of convection, rainfall, and latent heating occur in the Amazon basin (AMZ); however, there are relatively few detailed observations of the con-

Corresponding author address: Dr. Walter A. Petersen, Dept. of Atmospheric Science, Colorado State University, Fort Collins, CO 80523-1371.

E-mail: walt@radarmet.atmos.colostate.edu vection, and more specifically, convective structure over the AMZ. Satellite-based studies utilizing special sensor microwave Imager (SSM/I) passive microwave (e.g., Mohr et al. 1999) and optical transient detector (OTD) lightning data (Toracinta and Zipser 2001) suggest that in the mean, wet-season convection over the AMZ is distinctly different from that of other continental locations such as tropical Africa or the Maritime Continent region. Indeed, studies utilizing various combinations of the Tropical Rainfall Measuring Mission (TRMM) 


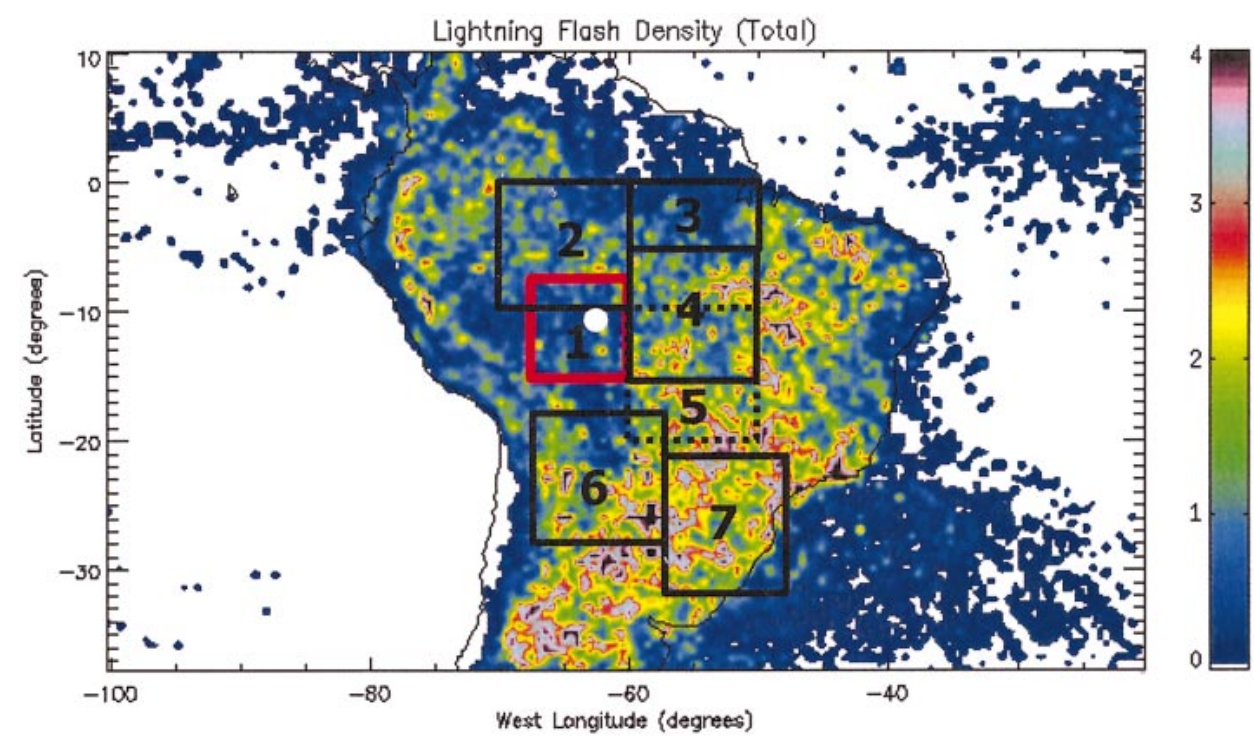

FIG. 1. Map of South America with mean lightning flash density (shaded; flashes $\mathrm{km}^{-2} \mathrm{month}^{-1}$ ) for the wet seasons of Dec-Mar 1998-2000. Regions of analysis examined in this study are indicated by numbered boxes (see Table 1). The red box indicates the region in which TRMM-LBA was held. The location of the Abracos Hill rawinsonde site is indicated by a white dot.

satellite precipitation radar, lightning, and passive microwave observations (Nesbitt et al. 2000; Boccippio et al. 2000; Petersen and Rutledge 2001) suggest that wetseason convection over the Amazon typically possesses a precipitation vertical structure that is somewhat intermediate to that observed over tropical oceans (less lightning, less vertically developed) and continents (more lightning, robust vertical development). These results suggest that in model-based retrievals of hydrometeor, rainfall, and/or latent heating profiles (e.g., Tao et al. 1990, 1993; Kummerow and Giglio 1994) over the AMZ, it may not be sufficient to feed inversion algorithms with normalized profiles of the aforementioned variables based on studies of convection conducted over other tropical continents.

In addition to wet-season intercontinental differences in convective structure, the vertical structure of convection over the $\mathrm{AMZ}$ exhibits a pronounced seasonal variability. Just prior to the wet season in the so-called transition period (e.g., September-November), AMZ convection is much more continental, exhibiting a greater frequency of deep radar reflectivity cores (e.g., reflectivities $\geq 30 \mathrm{dBZ}$ ) and more frequent lightning (Petersen and Rutledge 2001). To first order, the satellite observations suggest that seasonal mean convective vertical structure and lightning characteristics in the AMZ (Fig. 1) represent two dominant modes of convective vertical structure often referred to in the literature to describe convection in the Tropics: oceanic and continental (Rutledge et al. 1992; Williams et al. 1992; Zipser and Lutz 1994; Nesbitt et al. 2000).

On a seasonal timescale, changes in Amazonian convective structure (Petersen and Rutledge 2001) are likely modulated by changes in the thermodynamic and dynamical structure of the troposphere associated with transitions between wet and dry seasons (Fu et al. 1999; Marengo et al. 2001). Additionally, seasonal variability in aerosol loading [e.g., the cloud condenstation nuclei (CCN) concentration] may influence the seasonal mean convective structure (Rosenfeld and Lensky 1998; Williams et al. 2002, hereafter WIL). Variability in atmospheric forcing of convection also occurs on intraseasonal timescales over the AMZ (Garreaud and Wallace 1998; Liebman et al. 1999; Rickenbach et al. 2002, hereafter RFHS; Carvalho et al. 2002, hereafter CJS). Hence, as in other locations of the Tropics (e.g., over the Maritime Continent region of northern Australia; Rutledge et al. 1992; Williams et al. 1992; Cifelli and Rutledge 1998), it is likely that intraseasonal variability over Amazonia is also reflected in modes of convective vertical structure that appear on similar timescales.

Indeed, recent ground-based radar observations of convection in the southwestern Amazon (AMZ) collected during the 6-week TRMM-Large-scale Biosphere-Atmosphere Experiment in Amazonia (LBA) field campaign (January-February 1999; Silva Dias et al. 2002) suggest that wet-season convective characteristics possess two general modes (RFHS; Cifelli et al. 2002, hereafter CPCR). During TRMM-LBA these modes were most obviously manifested in the convective vertical structure, associated cloud-to-ground (CG) lightning flash density, and rainfall statistics. In turn, changes in the mode of convection were highly correlated to changes in the $850-700-\mathrm{mb}$ zonal wind direction (CPCR; RFHS; WIL; CJS). For example, during periods of westerly (easterly) $850-\mathrm{mb}$ zonal wind, the 
vertical structure of convection was observed to be more oceanic/monsoon (continental)-like, exhibiting weaker (stronger) updrafts, relatively shallow (deep) radar reflectivity cores, and reduced (copious) amounts of lightning. Accompanying the changes in convective vertical structure, westerly (easterly) regime convection tended to produce relatively larger (smaller) areas of lighter (heavier) rainfall (RFHS; CPCR) as reflected in a narrower (broader) distribution of rainfall rates (CPCR). Further, characteristic changes in the raindrop size distribution appear to occur between the regimes, with smaller (larger) median volume drop diameters occurring in westerly (easterly) regimes (A. Tokay 2001, personal communication; Carey et al. 2001). Recent findings from TRMM-LBA have also noted decreases in CCN concentration, lightning flash count, convective available potential energy (CAPE) and convective inhibition (CIN) during westerly regimes (Halverson et al. 2002; WIL). In addition, the diurnal cycle of rainfall observed during the westerly (easterly) regimes of TRMM-LBA was less (more) peaked (RFHS). In many respects the regime differences in convective vertical structure and electrical activity observed over southwestern Amazonia during TRMM-LBA are similar to those documented for monsoon and break-period regimes in tropical northern Australia (Rutledge et al. 1992; Williams et al. 1992; Cifelli and Rutledge 1998).

In order to expand upon the temporally and spatially limited observations collected during TRMM-LBA, we examine continental-scale, multiple wet-season eastwest regime changes in convective vertical structure and associated lightning activity over the AMZ and subtropical South America (Fig. 1). To accomplish this task we combine TRMM satellite precipitation radar (PR), microwave imager (TMI), lightning imaging sensor (LIS), and Brazilian Lightning Detection Network (BLDN) data with $850-700-\mathrm{mb}$ zonal wind data [National Centers for Environmental Prediction-National Center for Atmospheric Research (NCEP-NCAR) reanalysis; Kalnay et al. 1996]. The 850-700-mb winds are utilized in order to maintain consistency with TRMM-LBA observations. Analysis of the aforementioned observations provides a means for placing the TRMM-LBA "regime" observations into a more climatological framework.

More specifically, we address the following questions: Relative to the observations documented for TRMM-LBA, how robust are regime trends in Amazonian convective vertical structure when considered temporally over multiple wet seasons and spatially over a continental-scale domain? Do associated changes in convective vertical structure occur in locations surrounding the Amazon? If the bimodal relationship in convective vertical structure observed during TRMMLBA is robust, then the results of this study combined with those of TRMM-LBA (e.g., CPCR; Halverson et al. 2002; RFHS; WIL; CJS). may have important implications for rainfall estimation, latent heating retriev-
TABLE 1. Analysis regions.

\begin{tabular}{|c|c|}
\hline $\begin{array}{l}\text { Box number } \\
\text { (Fig. 1) }\end{array}$ & Location \\
\hline 1 & $\begin{array}{l}\text { SWAMZ; }\left(7.5^{\circ}-15^{\circ} \mathrm{S} ; 67.5^{\circ}-60^{\circ} \mathrm{W}\right) ; \mathrm{TRMM}- \\
\quad \text { LBA }\end{array}$ \\
\hline 2 & West-central Amazon $\left(0^{\circ}-10^{\circ} \mathrm{S} ; 70^{\circ}-60^{\circ} \mathrm{W}\right)$ \\
\hline 3 & East-central Amazon $\left(0^{\circ}-5^{\circ} \mathrm{S} ; 60^{\circ}-50^{\circ} \mathrm{W}\right)$ \\
\hline 4 & South-central Amazon $\left(5^{\circ}-15^{\circ} \mathrm{S} ; 60^{\circ}-50^{\circ} \mathrm{W}\right)$ \\
\hline 5 & Mato Grosso $\left(10^{\circ}-20^{\circ} \mathrm{S} ; 60^{\circ}-50^{\circ} \mathrm{W}\right)$ \\
\hline 6 & $\begin{array}{l}\text { Altiplano region (including plains to the east; } \\
\left.\qquad 18^{\circ}-28^{\circ} \mathrm{S} ; 67.5^{\circ}-57.5^{\circ} \mathrm{W}\right)\end{array}$ \\
\hline 7 & Southern Brazil $\left(21^{\circ}-34^{\circ} \mathrm{S} ; 57.5^{\circ}-47.5^{\circ} \mathrm{W}\right)$ \\
\hline
\end{tabular}

als, and cumulus parameterization over the Amazon region.

\section{Data and methodology}

Three full wet seasons (December-March, 1997-98, 1998-99, and 1999-2000) of TRMM satellite data were partitioned into easterly and westerly regimes. The partitioning methodology used was based on the aforementioned relationship (section 1) between low- to midlevel wind direction and convective structure observed in easterly and westerly wind regimes over the southwestern Amazon (SWAMZ) during TRMM-LBA (RFHS; CPCR). Since the TRMM-LBA easterly and westerly regimes were highly correlated to changes in the continental-scale circulation over South America (RFHS), the regime partitioning method employed in this study made exclusive use of the zonal wind direction observed over the SWAMZ (Table 1; see also box 1 in Fig. 1). To the extent that "convective regimes" (e.g., intraseasonal variability) occurring in the SWAMZ are a reflection of large-scale continental controls on convection, this partitioning methodology when utilized over multiple wet seasons should also reveal associated changes in convective structure and the large-scale circulation over other regions of tropical and subtropical South America. The combined applicability, simplicity, and availability of both $850-700-\mathrm{mb}$ zonal wind and cloud-to-ground lightning data (a proxy for convective structure) provided an expedient means for determining east and west partitions over periods extending well beyond the 6-week TRMM-LBA sampling period (e.g., the full 1998-99 wet season, and the wet seasons of 1997-98 and 1999-2000).

In order to partition each of the three wet seasons into east and west regimes, gridded zonal winds at 850 mb were utilized to compute daily, low-level, area mean zonal wind directions for a box covering the TRMMLBA domain in the SWAMZ $\left(7.5^{\circ}-15^{\circ} \mathrm{S}, 68^{\circ}-60^{\circ} \mathrm{W}\right.$; Table 1, Fig. 1). These winds were then smoothed (5day running mean) and plotted in time series form. To ensure that trends in the NCEP-NCAR wind data were representative, a time series of SWAMZ area mean 850$\mathrm{mb}$ zonal wind (normalized) was compared to a similar time series observed over the TRMM-LBA Abracos 


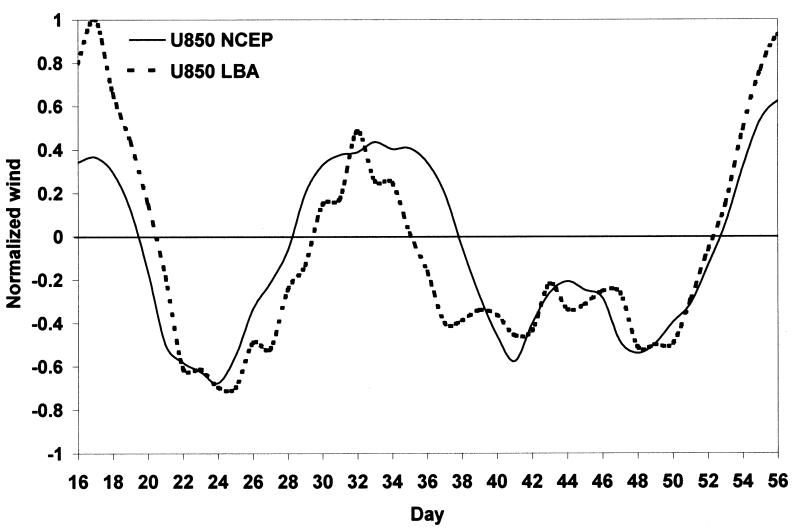

FIG. 2. Normalized zonal wind time series (5-day running mean) for TRMM-LBA time period Jan-Feb 1999. Area mean NCEPNCAR reanalysis winds covering the TRMM-LBA analysis domain (box 1; Fig. 1) are indicated by a solid line. Winds observed at the Abracos Hill sounding site (TRMM-LBA) are indicated by a dashed line.

Hill sounding site (located at $10.75^{\circ} \mathrm{S}, 62.35^{\circ} \mathrm{W}$ ) during January-February 1999 (Fig. 2). Importantly, the TRMM-LBA sounding data have not been assimilated into the NCEP-NCAR reanalysis data used herein, thus the two datasets provide independent measures of the tendency in zonal wind direction for comparison. While the smoothed Abracos Hill winds represent only a single data point in the TRMM-LBA domain, trends in the Abracos zonal wind were highly correlated to zonal winds observed at all four of the TRMM-LBA sounding locations (J. Halverson 2001, personal communication), hence the Abracos Hill winds are taken to be representative of the region as a whole. The favorable comparison between trends in the normalized NCEP-NCAR and Abracos zonal wind time series (Fig. 2) supports the use of NCEP-NCAR 850-mb zonal winds as an objective means for identifying easterly and westerly regimes over multiple wet seasons.

Utilizing the smoothed time series of zonal wind created for each wet season, intervals of easterly and westerly wind direction could be easily identified and partitioned into regimes. As a simple way to test the validity of this partitioning method, the partitioned wind time series was subsequently compared to a 5-day running mean time series of CG lightning data collected by the BLDN $^{1}$ (Blakeslee et al. 1999) for the 1998-99 and 1999-2000 wet seasons (cf. section 3 and Fig. 5). We compared the partitioned zonal winds to lightning data for two reasons: 1) during TRMM-LBA, CG lightning tendencies were highly correlated to regime changes in convective vertical structure; and 2) the temporal continuity of the CG lightning data provide a robust means

${ }^{1}$ This network consists of four advanced lightning direction finders that detect and locate cloud-to-ground lightning flashes over the TRMM-LBA domain and surrounding areas of the SWAMZ. The network is still in operation. to detect temporal trends in both the frequency and/or intensity of convection over a large portion of the SWAMZ. The lightning-zonal wind comparison suggested that anomalies in the zonal wind speed (e.g., relative maxima and minima) were far better correlated to peaks in CG lightning activity than the absolute $d i$ rection of the zonal wind (as observed during TRMMLBA). Hence the partitioning methodology was refined by requiring relative maxima in the time series of 850$\mathrm{mb}$ zonal wind anomalies to exceed 1 standard deviation of the seasonal mean (also consistent with TRMM-LBA data) prior to a given time period being identified as either a "westerly" or "easterly" regime. ${ }^{2}$

Having identified easterly and westerly regimes for each wet season, TRMM PR convective vertical structure and LIS lightning statistics were subsequently computed for each regime over the three wet seasons for several different areas in the vicinity of the Amazon basin (Fig. 1; Table 1). First, three-dimensional radar reflectivity histograms were created by binning PR reflectivities by height (1-km bins), reflectivity (5-dBZ bins beginning at $20 \mathrm{dBZ}$ ) and relative frequency for all TRMM 2A-25 algorithm "rain-certain" PR pixels ( $\sim 4.3-\mathrm{km}$ footprint) that were geolocated in the regions and regimes being studied (cf. Petersen and Rutledge 2001). Approximately $2-4 \times 10^{6}$ reflectivity pixels per location were used to create each reflectivity histogram. Relative frequencies were computed for the histograms by taking the number of points in each reflectivity bin and dividing by the total number of reflectivity pixels at each height level. In addition to the reflectivity statistics, rainfall rate distributions were created utilizing rain rates from the TRMM PR 2A-25 algorithm (Iguchi and Meneghini 1994; Meneghini et al. 1999; Iguchi et al. 2000).

To complement analysis of the pixel-based reflectivity histograms, especially over the south-central AMZ where the signal of the regimes turned out to be the strongest (cf. section 3, Fig. 4), individual precipitation features ( $\mathrm{PFs}$ ) were identified and cumulative distribution functions (CDFs) were computed for the ensemble of PFs utilizing both PR reflectivities and TMI brightness temperatures (37- and 85-GHz channels). To identify the PFs, the PR and TMI data were collocated within the 220-km-wide PR swath to identify contiguous areas of PR rainfall and TMI 85-GHz ice scattering (cf. Nesbitt et al. 2000). The PF areas were required to be at least 4 PR pixels in size $\left(\sim 75 \mathrm{~km}^{2}\right)$ and to contain either PR near-surface reflectivities $>20 \mathrm{dBZ}$ or $85-\mathrm{GHz}$ polarization corrected temperatures (PCTs; Spencer et al. $1989)<250 \mathrm{~K}$. The PFs were then classified by their

\footnotetext{
${ }^{2}$ Note that meridional perturbations in the wind also occur with regime transitions, such that one could also partition the data into equivalent "northerly" or "southerly" regimes. There is some preliminary evidence to suggest that a partition based on meridional winds would yield results similar to the zonal partitioning method used herein (R. Fu 2001, personal communication).
} 
radar and ice scattering properties into three categories: precipitation feature without ice scattering ( $\mathrm{PCT}>250$ $\mathrm{K}$ at $85 \mathrm{GHz}$ ), precipitation feature with ice scattering (at least 1 pixel with $85-\mathrm{GHz} \mathrm{PCT}<250 \mathrm{~K}$ ), and precipitation feature with a mesoscale convective system [MCS; PF contained at least $2000 \mathrm{~km}^{2}$ of contiguous area with $85-\mathrm{GHz} \mathrm{PCT}<250 \mathrm{~K}$ and $185 \mathrm{~km}^{2}$ with 85 $\mathrm{GHz} \mathrm{PCT}<225 \mathrm{~K}$ to ensure a large convective system analogous to the Mohr and Zipser (1996) and Houze (1993) ice scattering and radar MCS definitions, respectively]. These precipitation features were identified for all TRMM satellite overpasses that occurred over the south-central Amazon during the three wet seasons examined.

Finally, because (i) lightning frequency was observed to vary as a strong function of regime during TRMMLBA (e.g., WIL); and (ii) the presence or absence of lightning can be utilized at least as a qualitative indicator for kinematic intensity and mixed phase microphysical processes, LIS lightning flash densities for each regime were also computed over the South American continent for grid boxes of $0.5^{\circ} \times 0.5^{\circ}$ for comparison to the PR and TMI datasets (Fig. 1). The BLDN data were similarly utilized as a regime metric (e.g., diurnal cycle comparisons) for the SWAMZ for the last two wet seasons (1999 and 1999-2000).

\section{Continental-scale flow and lightning activity in east and west regimes}

RFHS suggested that intraseasonal flow transitions from easterly to westerly in the southern AMZ (over the TRMM-LBA domain in particular) and along the South Atlantic convergence zone (SACZ) are associated with the periodic intrusion of frontal systems/baroclinic waves into the Tropics (Garreaud and Wallace 1998; Liebmann et al. 1999). These frontal boundaries tend to become quasi-stationary in the Tropics, assuming a northwest to southeast orientation, and modulate the intensity of convection along the climatological position of the SACZ on submonthly timescales (e.g., Liebmann et al. 1999). RFHS noted that these fronts are often accompanied by a westward movement of the Bolivian high and/or westward movement of a semipermanent upper-level (200-mb) cyclonic circulation that is typically located over northeastern Brazil during austral summer. Hence, it is likely that the two convective regimes identified in this study, based on zonal wind anomalies over the SWAMZ, should be reflected in synoptic-scale regime composites of the flow over a large portion of central and southern continental South America. Indeed, when the vector winds over South America are composited for multiple wet seasons at the 850- and 700 -mb levels for each regime clear differences in the synoptic-scale flow become apparent.

For example, at the 700-mb level, both the westerly (Fig. 3a) and easterly (Fig. 3b) regime composites indicate the presence of a synoptic-scale anticyclonic fea-
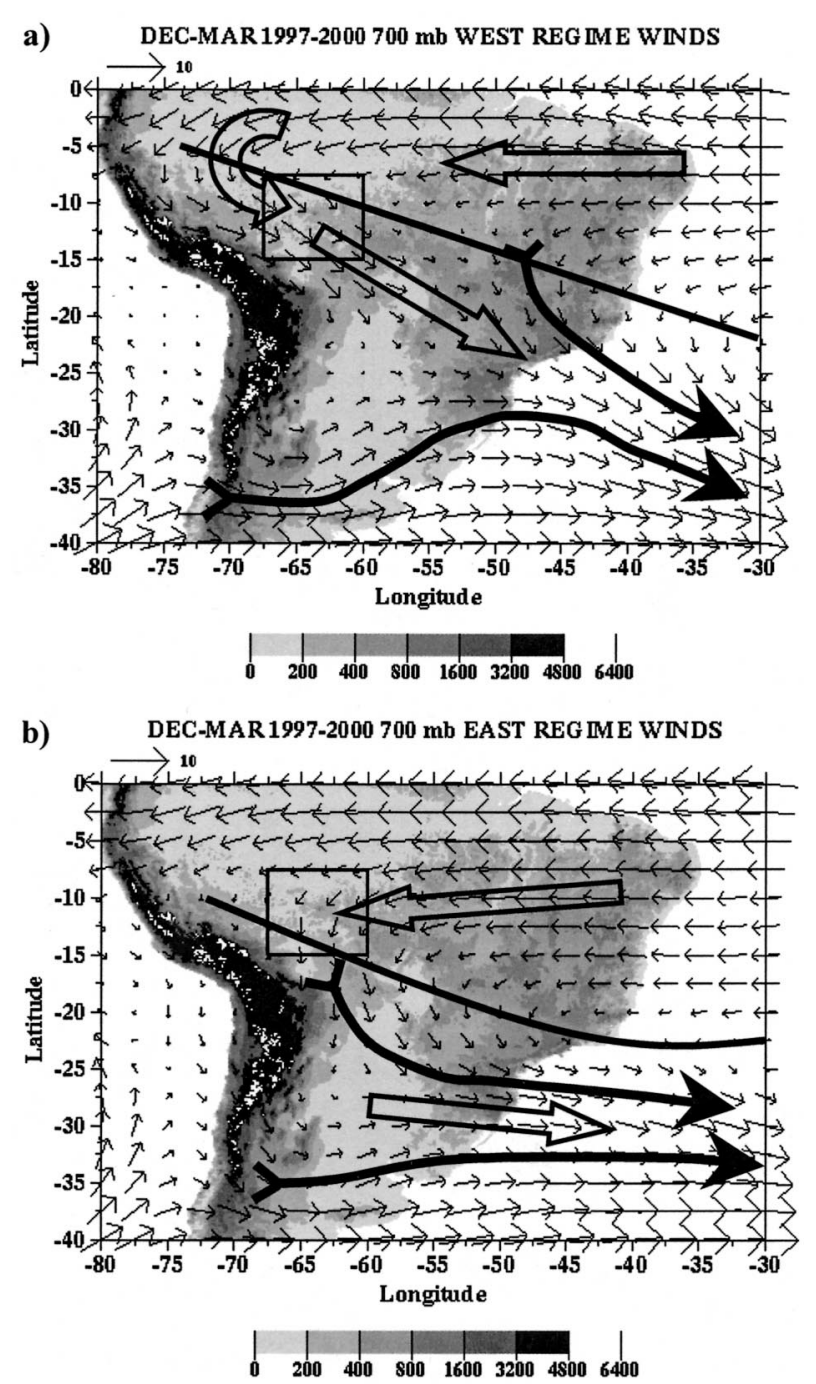

FIG. 3. South America 3-yr mean 700-mb winds by regime for the wet seasons of 1997-2000; (a) westerly and (b) easterly. Rondonia (TRMM-LBA domain) indicated by box. Topography is shaded as indicated.

ture in the wind field (Southern Hemisphere convention) that extends from the northwest to southeast and is ultimately associated with the South Atlantic high. During westerly (easterly) regimes, the axis of this flow feature is shifted toward the north (south) of the southern AMZ resulting in enhanced northwesterly (northeasterly) flow over and adjacent to the SWAMZ and reduced (enhanced) easterly flow farther to the east in the southcentral AMZ. To the south $\left(30^{\circ}-35^{\circ} \mathrm{S}\right)$, the presence of a midlatitude wave is indicated in the westerly regime at $700 \mathrm{mb}$ (more enhanced at $850 \mathrm{mb}$ - not shown), but is much less pronounced during the easterly regimes. Coincident with the presence of enhanced northwesterly flow along the Andes, the midlatitude wave, and northward movement of the ridge axis in the westerly composite, confluence of the northwesterly flow into the 
SACZ is enhanced. This is consistent with the presence of a more pronounced SACZ observed in satellite imagery during westerly events (Liebmann et al. 1999; RFHS).

Relative differences in the flow and convective intensity between the two regimes at the continental scale become more apparent when examining a differencevector map of the $850-\mathrm{mb}$ winds over most of South America together with spatially filtered (3-step Leise) lightning data from the LIS (Figs. 4a-b). In Fig. 4a, enhanced northwesterly flow (e.g., northwesterly jet; Nogues-Paegle and Mo 1997; Marengo et al. 2001) is present during the westerly regimes along the foothills of the Andes and over the southern AMZ. To the southeast, over the coast of Uruguay and Argentina $\left(35^{\circ} \mathrm{S}\right.$, $53^{\circ} \mathrm{W}$ ) the flow is more cyclonic during westerly regimes. The aforementioned synoptic-scale features present in Figs. 3-4 are consistent with the influence of periodic extratropical disturbances on the flow regime of the southern AMZ and central to southern South America (e.g., Garreaud and Wallace 1998; Lenters and Cook 1999; Liebmann et al. 1999; RFHS; CJS).

It is interesting to note that the submonthly timescale changes in wind flow between the regimes represented in Fig. 4 (composited means) are quite similar to the 10-yr mean January climatological anomalies presented by Zhou and Lau (1998) to support the presence of a South American "monsoon." Of the three wet seasons that were averaged in our analysis, westerly regimes tended to dominate the percentage of time spent in either regime during the wet season $(>60 \%)$. Considering this fact, in combination with the results of Zhou and Lau (1998) and those of Fig. 4, it may be that westerly anomaly regimes are more representative of the Zhou and Lau "monsoonlike" conditions over South America after averaging the submonthly westerly periods over multiple wet seasons. ${ }^{3}$ If this is the case, then easterly and westerly regimes in the southern AMZ may be analogous to alternating active-monsoon and monsoonbreak conditions observed in other regions of the Tropics such as tropical northern Australia (e.g., Holland 1986). In the case of South America, the submonthly modulator of monsoon or break conditions may be the large-scale circulation in the form of extratropical baroclinic waves (e.g., Liebmann et al. 1999; RFHS).

Though perhaps an oversimplification, to the extent that low to midlevel flow regimes in the southern AMZ are analogous to "break" and monsoon periods, we expect to observe marked changes in the vertical structure of convection as a function of regime (e.g., Rutledge et al. 1992; Williams et al. 1992; Cifelli and Rutledge 1998). Indeed, changes in lightning flash density (Figs. $4 \mathrm{a}-\mathrm{b}$ ) suggest that such changes do occur as a function

\footnotetext{
${ }^{3}$ Note that the large-scale mechanisms responsible for transitions between the regimes are likely to be numerous (e.g., Nogues-Paegle and Mo 1997; Garreaud and Wallace 1998; Lenters and Cook 1999; Liebmann et al. 1999; RFHS) and are beyond the scope of this study.
}
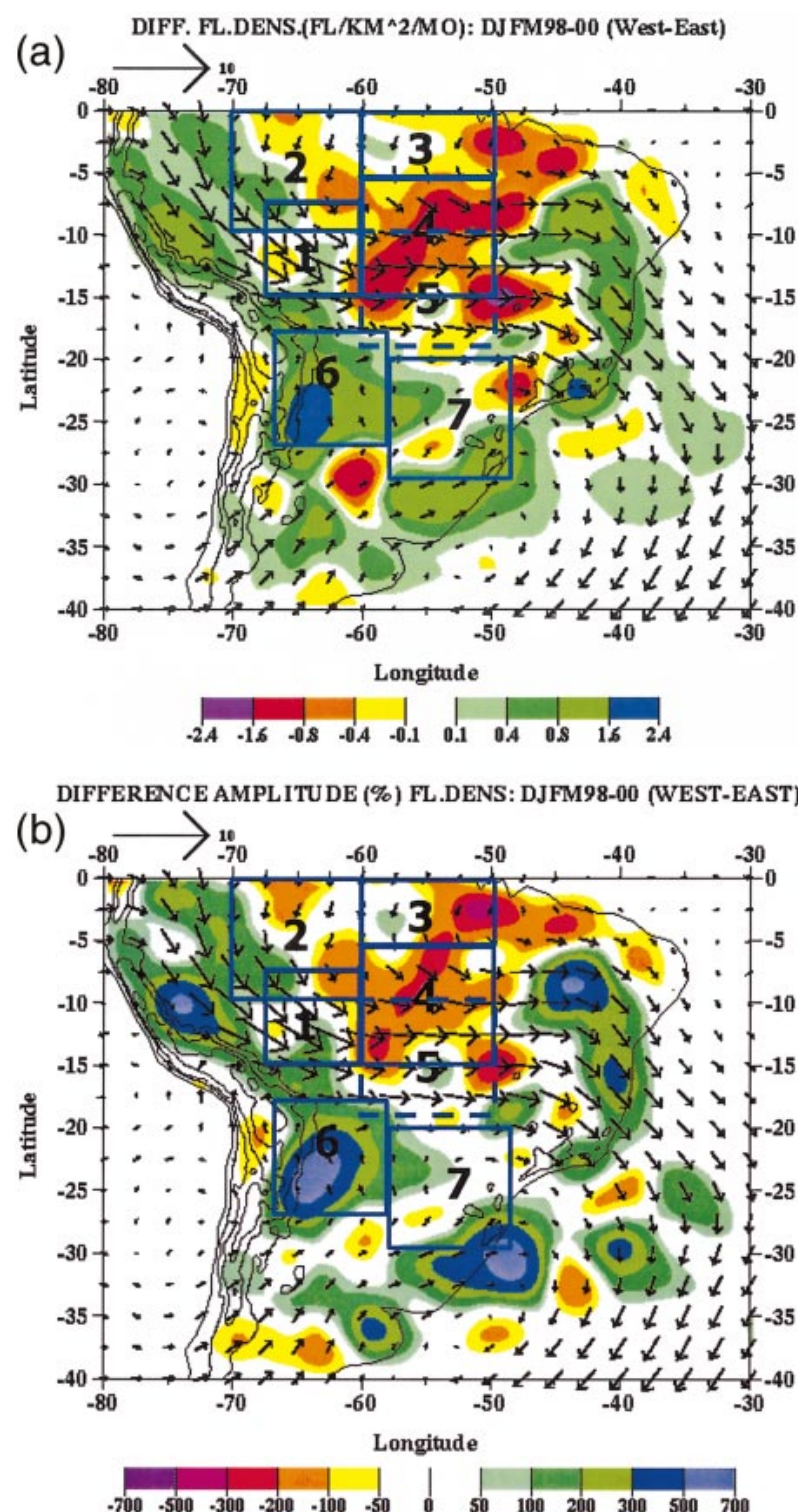

FIG. 4. (a) Difference (west - east) in regime vector winds at 850 $\mathrm{mb}$ and LIS lightning flash density (shaded) over AMZ and southern South America averaged and spatially filtered (3-step Leise) over wet seasons from the years 1997 to 2000 . Cool (warm) colors indicate larger lightning flash densities during westerly (easterly) wind regimes. The PR analysis box locations are indicated. (b) As in (a) but lightning flash density differences expressed as percentage increases relative to the opposing regime. Warm (cool) colors indicate the percentage increase in lightning flash density that occurs during easterly (westerly) regimes relative to westerly (easterly) regimes. Topography contoured at the 0-, 1000-, 2500-, and 4000-m levels.

of low-level wind regime. For example, relative to westerly regimes a 100\%-200\% increase in lightning (statistically significant at the $80 \%-90 \%$ level) occurs over the south-central AMZ during easterly regimes (box 4, Figs. 4a-b), consistent with observations from TRMMLBA (WIL; CPCR). When low-level easterly flow dominates in the southern AMZ, CAPE, CIN, and CCN 
concentration are all increased relative to westerly regimes (Halverson et al. 2002), a situation more conducive to lightning production. The large-scale conditions during easterly regimes are also more conducive to enhanced dynamical forcing and organization of convective systems in association with eastward-propagating squall lines and mesoscale instabilities that originate on the east coast of tropical South America and propagate deep into the AMZ basin (e.g., Sun and Orlanski 1981; Silva Dias and Ferreira 1992; Garstang et al. 1994; Cohen et al. 1995). Therefore, during easterly regimes both relative increases in CAPE and convective forcing/organization favor more lightning-producing convection.

During westerly regimes, the central AMZ experiences a relative reduction in lightning activity. However, Figs. $4 a-b$ suggest that westerly regime lightning flash densities are significantly enhanced relative to easterly regimes $(100 \%-700 \%)$ to the south of the AMZ, over the Altiplano (box 6), the southern fringe of the SACZ including southern Brazil (portions of box 7), and along the central and southern coast of South America $\left(10^{\circ} \mathrm{S}\right.$, $40^{\circ} \mathrm{W}$ to $\left.40^{\circ} \mathrm{S}, 60^{\circ} \mathrm{W}\right)$. These differences are statistically significant at the $70 \%-90 \%$ level $(90 \%$ over the Altiplano). Enhanced lightning activity occurs along the southern fringe of the SACZ during westerly regimes as evinced by the presence of a broken to nearly solid northwest-southeast-oriented band of higher lightning flash densities that originates in the Andes (e.g., $0^{\circ}-5^{\circ} \mathrm{S}$ ) and extends from the Altiplano to the Atlantic Ocean off the coast of southern Brazil and Uruguay (Fig. 4a; $\left.\sim 35^{\circ} \mathrm{S}, 40^{\circ} \mathrm{W}\right)$. More intense convective activity would be expected over the Altiplano and along the southern edge of the SACZ during westerly regimes in association with southeastward transports of moisture out of the AMZ (e.g., Nogues-Paegle and Mo 1997; Lenters and Cook 1999), more pronounced north-south moisture gradients, and increased convergence/forcing associated with extratropical frontal disturbances (Garreaud and Wallace 1998; Liebmann et al. 1999; RFHS). Interestingly, the location of the northwest-southeastoriented band of enhanced lightning activity during westerly regimes (Fig. 4a) approximately coincides with a similarly oriented band of air with high values of equivalent potential temperature $\left(\theta_{e}\right)$ and enhanced convection discussed in Garreaud and Wallace (1998, their Fig. 9) and RFHS. Both RFHS and Garreaud and Wallace associate this band of high $\theta_{e}$ and convection with the equatorward propagation of midlatitude frontal systems. The presence of increased lightning activity along the band of high $\theta_{e}$ (and large gradients in $\theta_{e}$ ) is consistent with previously noted sensitivities between CAPE (a strong function of $\theta_{e}$ ) and lightning frequency (e.g., Williams et al. 1992; Petersen et al. 1996).

Relative decreases in lightning activity over the southern AMZ during westerly regimes (Fig. 4b) should not be interpreted as a decrease in the amount of convective activity. On the contrary, there is still widespread
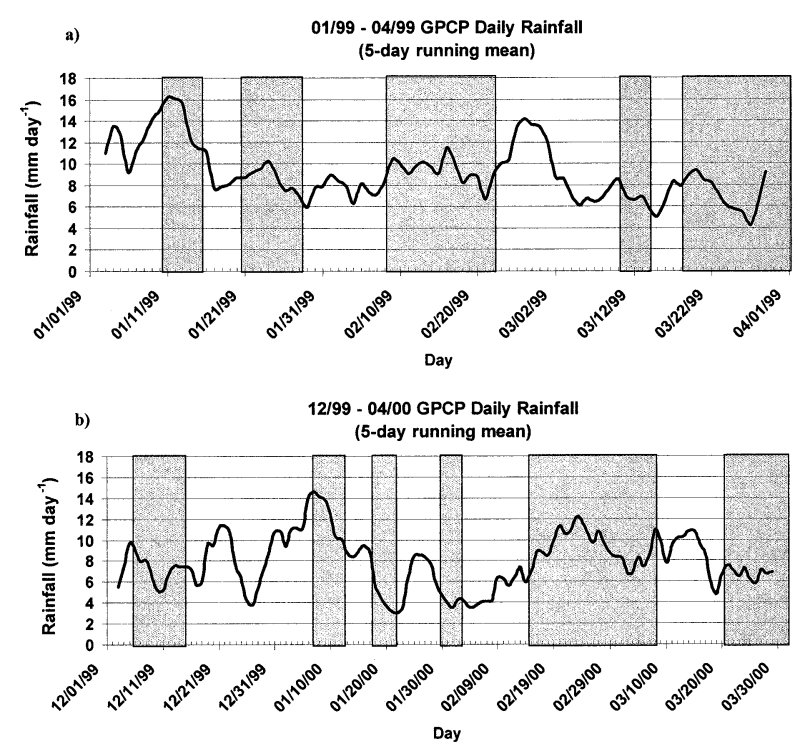

FIG. 5. Time series of GPCP $1^{\circ} \times 1^{\circ}$ daily rainfall $\left(\mathrm{mm} \mathrm{day}^{-1}\right)$ averaged over the area of box 1 in Figs. 1 and 4. (a) Jan-Apr 1999. (b) Dec 1999-Apr 2000. Shaded areas indicate easterly regime periods.

convection and rainfall over the AMZ during westerly regimes (e.g., RFHS; CPCR; CJS). This is clearly illustrated in Figs. 5a-b, which show 5-day running means of Global Precipitation Climatology Project (GPCP; Huffman et al. 1997) gridded daily mean rainfall $\left(1^{\circ} \times 1^{\circ}\right.$ grid) averaged over the SWAMZ (box 1 ; Fig. 4). Note that in the mean, daily rainfall over the SWAMZ during westerly regimes is often similar to that of easterly regimes. Though westerly regime cloud systems produce copious amounts of rainfall and exhibit considerable depth and area coverage, case studies from TRMM-LBA suggest that the vertical structure of westerly regime convection over the SWAMZ is associated with shallow reflectivity cores and relatively weak icephase processes (e.g., CPCR). These convective characteristics are similar to those typically associated with the vertical structure of tropical oceanic or monsoon convection. Hence it is expected that lightning flash densities should exhibit an overall reduction during westerly regimes in the southern AMZ relative to that observed during the easterly regime.

The enhancement in lightning that occurs along the coastline of tropical northeastern and eastern Brazil during westerly regimes $\left(\sim 15^{\circ} \mathrm{S}, 40^{\circ} \mathrm{W}\right.$; Fig. 4) may be associated with a combination of reduced low-level easterly flow off the Atlantic Ocean and elevated terrain located just inland. Northeastern Brazil is relatively arid, being located under subsidence associated with the South Atlantic ridge, hence any weakening in easterly trade winds may permit an eastward penetration of moisture and associated enhancements in conditional instability from the Amazon toward the coast (M. Silva Dias 2001, personal communication). Further, the difference 
a)

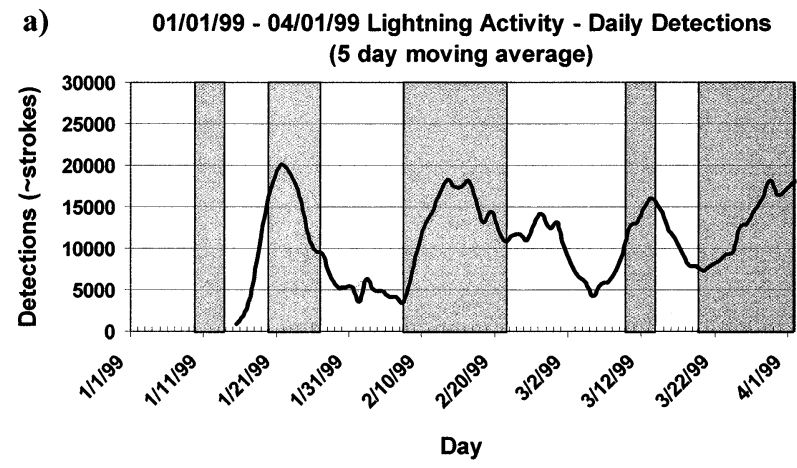

b)

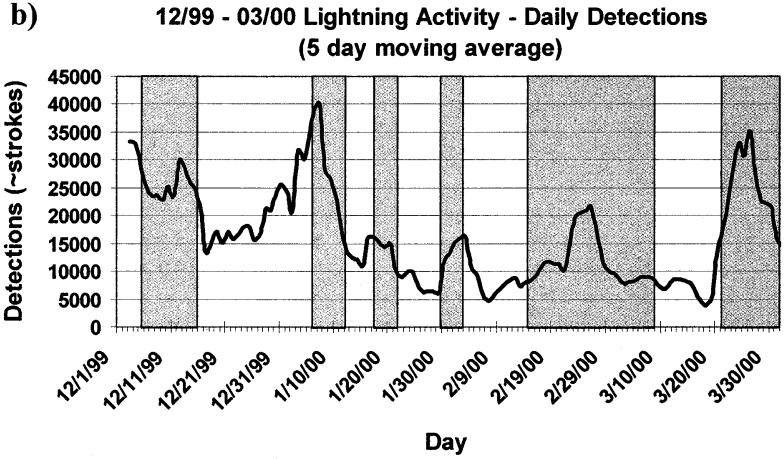

FIG. 6. Time series of BLDN stroke counts over the southwest AMZ for the wet seasons of (a) Jan-Mar 1999; and (b) Dec 1999Mar 2000. Yellow areas indicate easterly regime periods.

flow in Fig. 4 suggests that sea-breeze fronts would probably not be able to propagate as far inland during westerly regimes, resulting perhaps in more convergence just inland over elevated coastal terrain.

Somewhat surprisingly, over the SWAMZ where pronounced differences in convective vertical structure between easterly and westerly regimes were observed during the TRMM-LBA field campaign (RFHS; CPCR), the signal in LIS lightning flash density in Figs. 4a-b is somewhat mixed (relative to the south-central AMZ) even though the regime signal in the NCEP-NCAR 850mb winds remains quite pronounced across the entire SWAMZ box. By comparison, when ground-based lightning data from the BLDN are examined (Fig. 6) for the same region in time series form, the variability in lightning frequency between easterly and westerly regimes is robust and of the same character observed during TRMM-LBA and in the south-central AMZ. Specifically, for the SWAMZ analysis box during easterly (westerly) regimes there is a pronounced increase (decrease) in lightning activity. Regime variability in the BLDN data for this analysis box is further manifested when the diurnal cycles of lightning are examined (Fig. 7). In Fig. 7 the BLDN lightning data suggest a much more (less) amplified diurnal cycle during easterly (westerly) regimes, consistent with the diurnal cycles of rainfall for easterly and westerly regimes observed during TRMM-LBA (RFHS). Overall, the LIS data indicate similar regime trends in the diurnal cycles of lightning
SWAMZ: LIS/BLDN Diurnal Cycles of Lightning

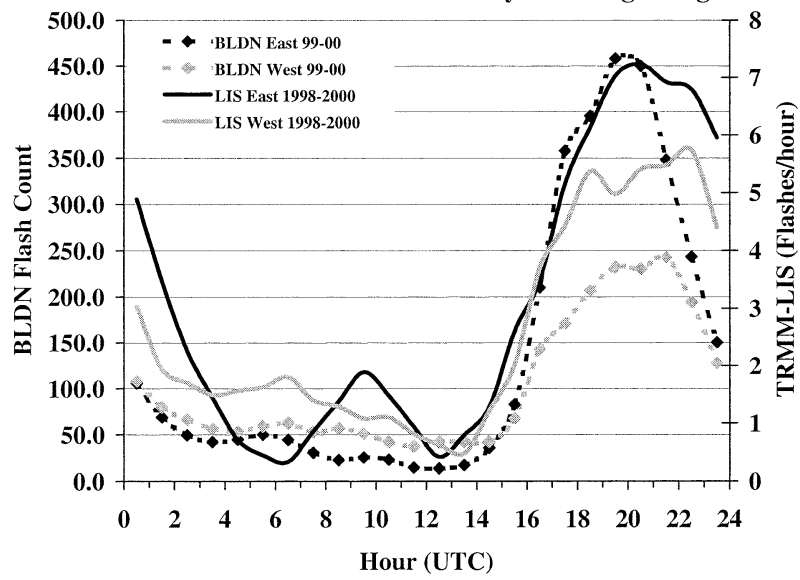

FIG. 7. Mean diurnal cycles of LIS and BLDN lightning flashes. BLDN (LIS) data are dashed (solid) with diamond markers. Westerly (easterly) regimes are gray (black) as indicated for each instrument.

for the SWAMZ (Fig. 7) but the differences between the two regimes are not as pronounced at those observed utilizing the BLDN data. These results suggest that (i) either the orbiting TRMM satellite is not capturing a complete sample of the regime variability across the SWAMZ box relative to a continuously sampling ground-based platform like the BLDN; or (ii) the SWAMZ box is located in a region where the regime signal in convection is in transition (e.g., the nature of the relationship between zonal wind direction, convective vertical structure, and lightning reverses).

To test option (ii) above, since the LIS data suggest a relatively strong regime signal in the south-central AMZ (Fig. 4) and in the far eastern portion of the SWAMZ box (which also contains the center of the TRMM-LBA domain), we partitioned the BLDN data in the SWAMZ along the $62.5^{\circ} \mathrm{W}$ meridian. We then examined the diurnal cycles and total flash counts for both sides of the SWAMZ box. The total flash count data suggest that the CG lightning flash density in the eastern side of the SWAMZ box is at least twice that of the western side. Hence, the LIS is far more likely to sample lightning flashes on the eastern side of the SWAMZ box relative to the western side. If the regime signals in the BLDN data for the entire SWAMZ box were excessively weighted by lightning occurring on the eastern side of the SWAMZ box, then discrepancies between the LIS, BLDN, and TRMM-LBA diurnal cycle observations could be explained by the location of the SWAMZ box convolved with changing regime controls on convection across the box. However, the BLDN diurnal cycles of lightning for both sides of the SWAMZ box still indicate a strong, consistent regime variability that is virtually identical to Fig. 7 (i.e., markedly more lightning in easterly regimes).

Hence, based on the BLDN data it seems likely that the same regime signal (e.g., more lightning during easterly periods) is observed in a continuous sense across 
the majority of the SWAMZ box. Incomplete sampling of the regimes by TRMM [e.g., option (i) above] may provide a reasonable explanation for both the mixed signal in regimes in the LIS data across the SWAMZ box (Fig. 4) and the difference in diurnal cycle between the LIS and BLDN datasets (Fig. 7). This is further evident when regime view times for the LIS instrument are compared for the SWAMZ box. For the 3-yr analysis period, there was approximately $50 \%-75 \%$ more view time over the SWAMZ during local afternoon hours (when the peak in the diurnal cycle of convection occurs; Fig. 7) of the westerly regime periods. Hence, the natural diurnal cycle of convection convolved with the sampling period of the TRMM satellite may also be affecting the degree to which the regime signal is being detected in the SWAMZ for the three wet seasons being studied.

In summary, easterly and westerly convective regimes in the southern AMZ, as defined by the direction of the 850-mb zonal wind in the SWAMZ (the TRMMLBA domain), appear to be the result of continentalscale circulations (e.g., RFHS). These regimes are manifested in the large-scale low- to midlevel flow, ${ }^{4}$ and for at least some locations over South America, appear correlated to proxies for convective intensity/frequency such as the lightning flash count.

\section{The vertical structure of convection in easterly and westerly regimes}

In addition to being linked to the presence or absence of lightning in deep convection, vertical structure is related to the profile of latent heating in deep convection through both water budget and dynamical feedbacks (e.g., Tao et al. 1990, 1993; Cartwright and Ray 1999; Yang and Smith 1999). Hence to the extent that variability in vertical structure varies as a function of lowlevel wind regime over the AMZ, accurate determination of the wind regime may yield important information as to the mean convective structure and associated microphysical processes occurring in a given region at any time. Since the amount of lightning is often indicative of certain types of convective structure (e.g., enhanced mixed phase processes), and east-west regime signals do appear in the LIS data (Figs. 4, 7), the regime signals discussed in section 3 are likely to be manifested in coincident precipitation data (acknowledging the possible sampling issues). Therefore, following the methodology outlined in section 2, in this section we utilize PR and TMI data to address the question of how vertical precipitation structure and rain rate distributions change as a function of regime for several locations over the South American continent.

\footnotetext{
${ }^{4}$ RFHS also note regime changes in the relative location of centers of semipermanent circulation features at $200 \mathrm{mb}$, such as the Bolivian high.
}

\section{a. Pixel-based PR statistics}

Three-dimensional histograms of regime precipitation vertical structure constructed from individual PR reflectivity pixels are shown in Fig. 8a for several locations in the Amazon basin and neighboring subtropical locations (boxes 1, 3, 4, 5, 6, 7; Fig. 1). Heavier precipitation is emphasized in Fig. 8a by focusing on layer relative frequencies of PR reflectivity pixels $\geq 30 \mathrm{dBZ}$. Relative frequencies at heights below $5 \mathrm{~km}$ are truncated in Fig. 8a to emphasize colder regions of the troposphere (cf. item 2 below). The reflectivity histograms suggest the following:

1) Systematic differences (significant at a $p=0.01 \mathrm{lev}$ el) in vertical structure between the regimes are most apparent in the south-central AMZ, Mato Grosso, Altiplano region, and over southern Brazil. Though weaker, regime differences are also apparent over the SWAMZ. Consistent with the Geostationary Operational Environmental Satellite (GOES) satellite analysis of CJS, there appeared to be very little difference in convective vertical structure detected as a function of regime by the TRMM satellite over the central and west-central AMZ (box 2, Fig. 1; not shown).

2) The most systematic differences in vertical structure are generally found at temperatures $\leq-10^{\circ} \mathrm{C}$, and are manifested as increases (decreases) in the relative frequency of reflectivity $\geq 30 \mathrm{dBZ}$ in easterly (westerly) regimes. Intense convection (e.g., reflectivities $>30 \mathrm{dBZ}$ at temperatures $\leq-10^{\circ} \mathrm{C}$ ) is $10 \%-20 \%$ more (less) likely over the SWAMZ during easterly (westerly) regimes and 30\%-50\% more (less) likely over the south-central AMZ during easterly (westerly) regimes. These vertical structure changes are consistent with an approximately $40 \%$ (11\%) increase in lightning flash density during easterly regimes in the southern (southwestern) AMZ.

3) Over the Altiplano and southern Brazil the situation is reversed. Westerly (easterly) regimes are associated with a marked increase (decrease) in the frequency of reflectivities $\geq 30 \mathrm{dBZ}$ at temperatures $\leq$ $-10{ }^{\circ} \mathrm{C}$. These changes are consistent with $60 \%$ and $25 \%$ increases in lightning flash densities over the Altiplano and southern Brazil, respectively, during westerly regimes.

To further elucidate the vertical profile changes in convective structure as a function of regime, relative frequencies associated with areas covered by boxes in the vicinity of the AMZ and south of the AMZ (e.g., the Altiplano and southern Brazil domains) were averaged for both easterly and westerly regimes, and subsequently normalized to express relative increases in the frequency of reflectivity pixels $\geq 30 \mathrm{dBZ}$ at any given height level. For the AMZ (Altiplano/southern Brazil) region we computed the difference in relative frequency between east and west regimes and divided by the west 
(a) Dec.-Mar. 1997-2000 TRMM-PR: $Z_{e}>30 \mathrm{dBZ}$ vs. Height

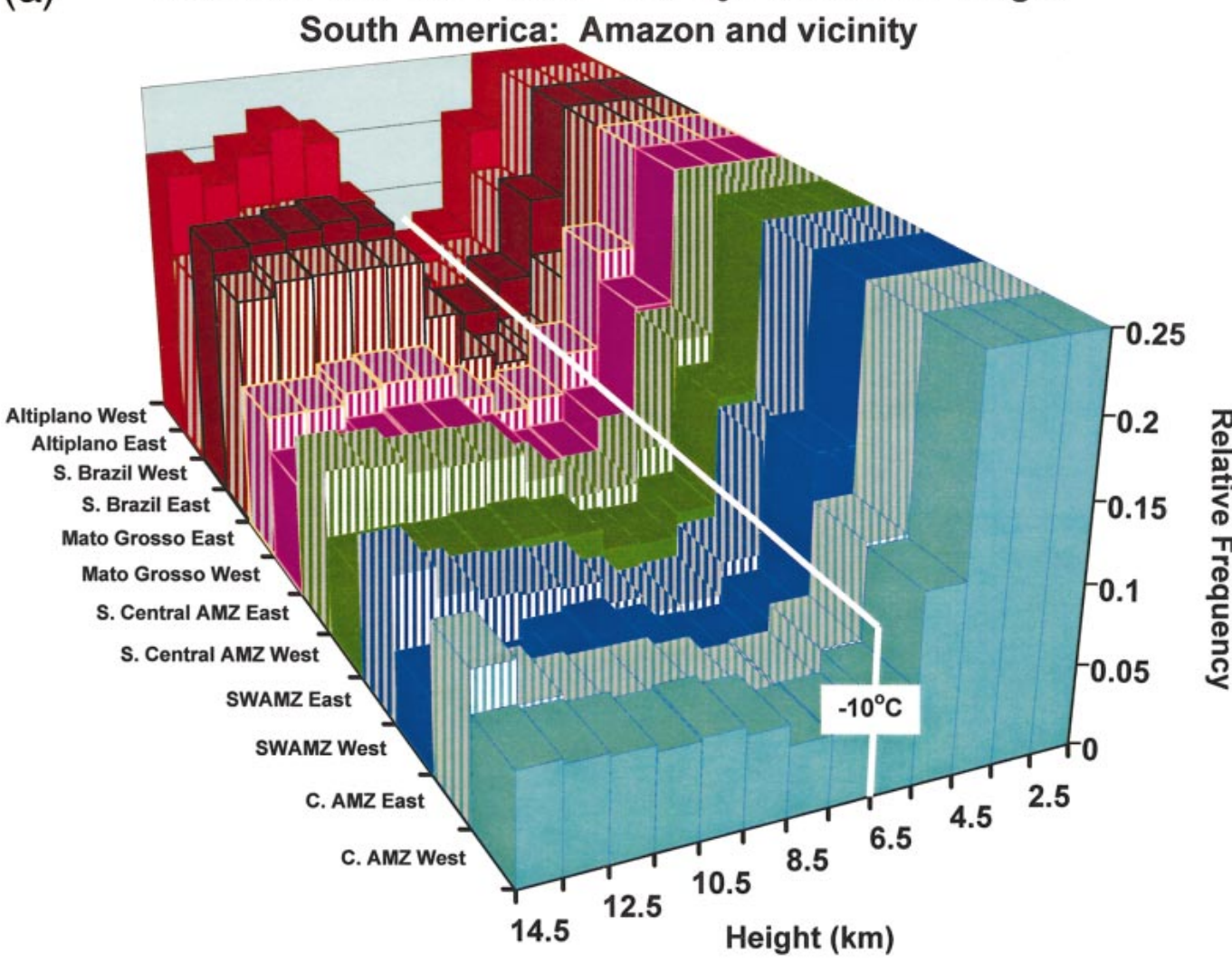

(b) Relative Change in Frequency $>30 \mathrm{dBZ}$

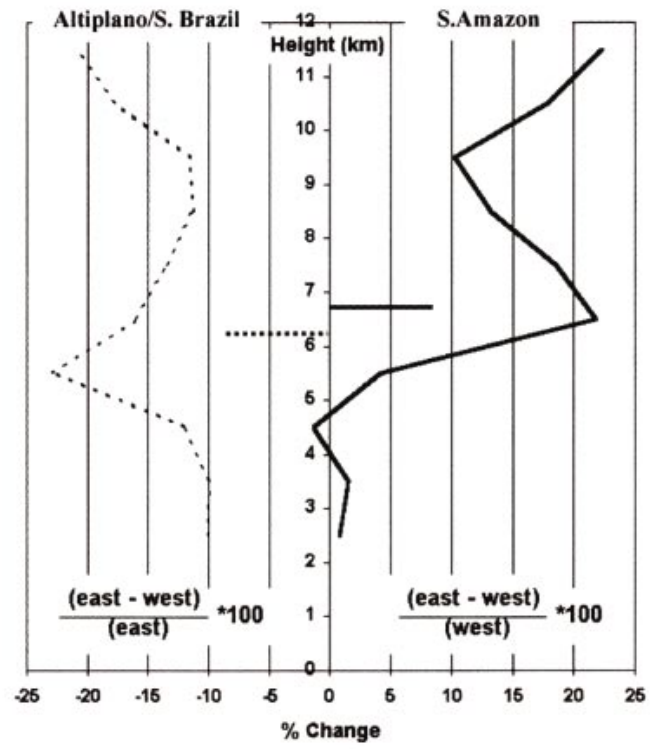

FIG. 8. (a) Wet-season (Dec-Mar 1998-2000) PR 2A-25 radar reflectivity (dBZ) relative frequency histograms as a function of height, regime, and location for $\mathrm{dBZ} \geq 30$. Easterly (westerly) regimes are indicated by striped (solid) colors. The approximate height of the $-10^{\circ} \mathrm{C}$ isotherm is also indicated by a bold white line. (b) Regime relative change in frequency of pixels $>30 \mathrm{dBZ}$ as a function of height. Solid line indicates mean relative changes expressed as a percent increase relative to westerly regimes for analysis boxes in the Amazon and vicinity. Dashed line indicates mean relative change for the Altiplano and southern Brazil analysis boxes expressed as a percent increase relative to the easterly regime. 


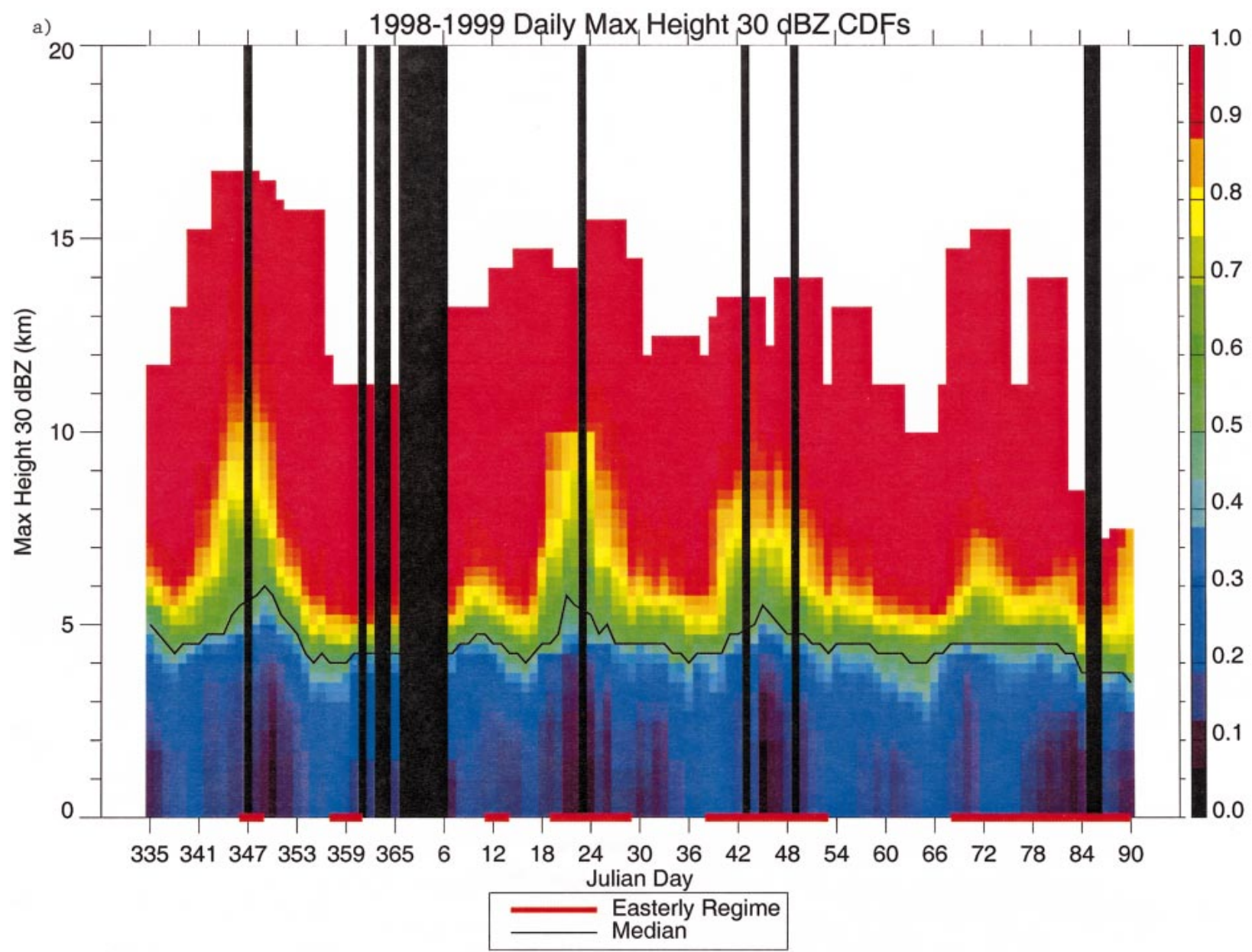

FIG. 9. Dec-Feb 1998-99 south-central Amazon time series of TRMM CDF for precipitation features. (a) The PR daily maximum height of 30-dBZ echo tops; (b) TMI daily minimum $85-\mathrm{GHz}$ (PCTs). Easterly regime periods are indicated by red horizontal lines located above the Julian day (abscissa), while the median level of the observation is indicated by the dark solid line. Missing data are indicated by black vertical lines/bars.

(east) regime relative frequency at each height level. This resulted in vertical profiles that indicate the percent change in $30-\mathrm{dBZ}$ frequency that occurs when transitioning from westerly to easterly regimes for each region (Fig. 8b).

For the AMZ region (primarily the southern AMZ where the signal was strongest in Fig. 8a), Fig. 8b clearly shows the very small mean difference in the vertical structure below the freezing level (e.g., $\sim 5 \mathrm{~km}$ ). However, as the altitude increases and temperature decreases, the fraction of reflectivity pixels exceeding $30 \mathrm{dBZ}$ systematically increases by an average of $10 \%-25 \%$ when transitioning from a westerly to an easterly regime. The Altiplano/southern Brazil mean profile is almost a mirror image of the AMZ profile, reflecting the reverse trend in this region for more intense vertical development in westerly regimes. If the profiles in Fig. $8 \mathrm{~b}$ are compared as a function of temperature instead of height, the profiles become almost exact mirror images (since the freezing level is slightly lower in subtropical/mid- latitude South America where the Altiplano and southern Brazil boxes are located). The common overall structure exhibited in both vertical profiles of Fig. 8b (e.g., height of peaks, etc.) also seems to point to a population of convection and/or convective characteristics that behave similarly as a function of regime changes in both locations.

The PR pixel-based results summarized in Figs. 8ab suggest that systematic regime differences in convective vertical structure occur on a continental scale and that these changes are also manifested in regime changes in lightning flash density. While being physically consistent with the TRMM-LBA observations and the LIS dataset, the large 3-yr sample of PR reflectivity pixels $\left[O\left(10^{6}\right)\right]$ also results in the regime differences (Fig. 8a) being statistically significant at a level exceeding a $p$ value of 0.01 (though spatial serial correlation is not accounted for). In order to place the pixel-based statistics within the framework of individual convective systems and to further verify the internal consistency of 


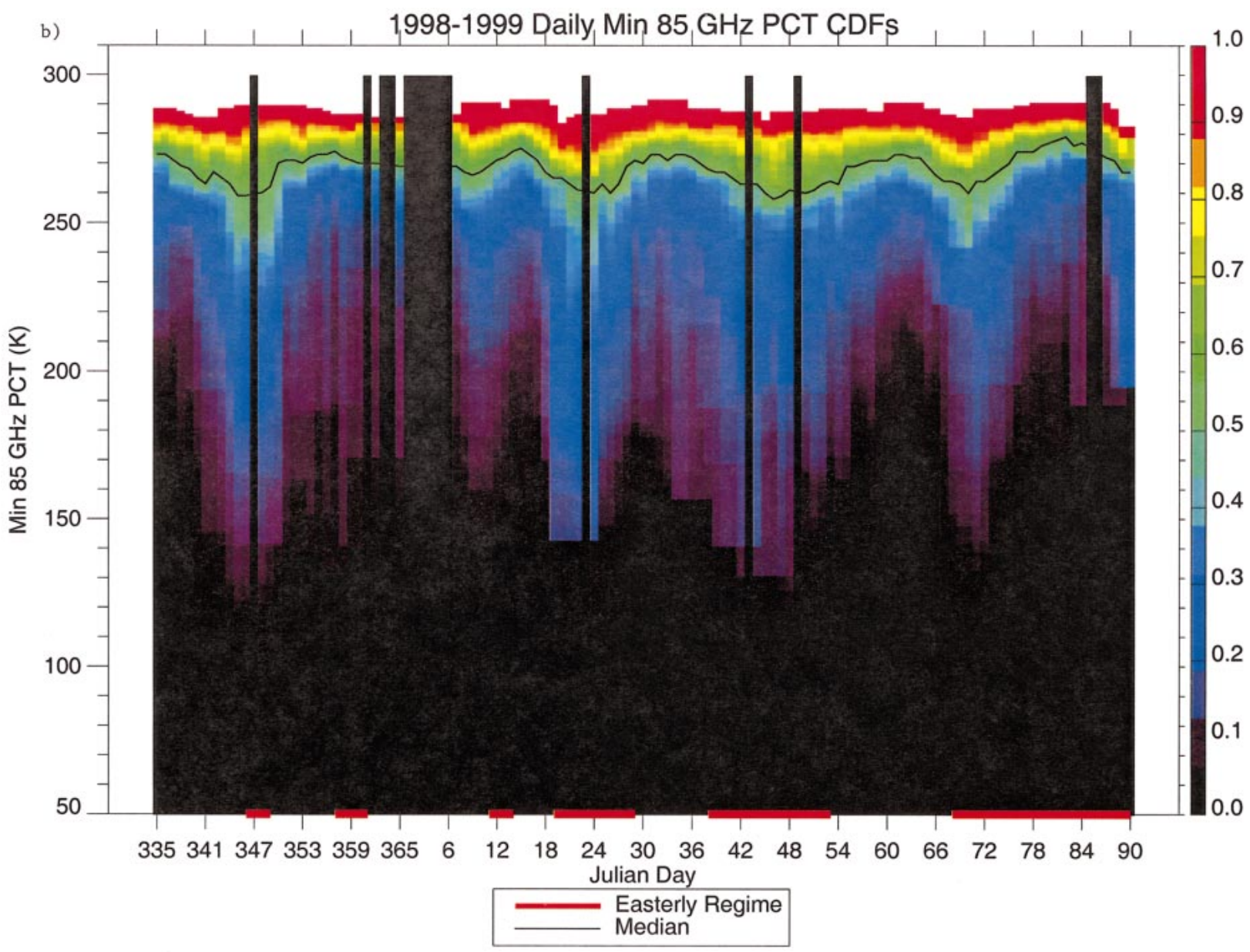

FIG. 9. (Continued)

the results, we also examine vertical structure statistics for individual precipitation features in each regime.

\section{b. Regime differences in precipitation features}

In this section we now describe PF statistics (cf. section 2) for the south-central AMZ analysis box, and extend the PR analysis by examining TMI brightness temperatures by regime for the ensemble of PFs. The number of TRMM satellite-identified PFs for the three wet seasons (1997-98, 1998-99, 1999-2000) separated by regime type and fraction of the season spent in each regime, is shown in Table 2. From the composite of all three wet seasons, it is evident that there is a slightly higher fraction of westerly regime days $(62.3 \%)$ than westerly regime PFs $(55.6 \%)(6392 / 5110+6392)$. This difference is increased when further partitioning PFs into those with $85-\mathrm{GHz}$ ice scattering signatures and/or those occurring with an MCS. Hence the PF analysis suggests there is a higher fraction of weak and/or small features occurring during the westerly regime. Systems with $\mathrm{PR}$ rain volume $>10^{3} \mathrm{~mm} \mathrm{~h}^{-1} \mathrm{~km}^{2}$ do not follow this regime distinction; an equal likelihood of finding these larger rain producers occurs in both regimes.

Significant variability in the number of regime days occurs among the three examined wet seasons. The 1998-99 wet season (when the TRMM-LBA field experiment was conducted) contained a higher fraction of easterly regime days than the other two seasons. As a result, a higher fraction of features with $85-\mathrm{GHz}$ ice scattering signatures (brightness temperature $<250 \mathrm{~K}$ ) were detected. The other two seasons contained roughly 2:1 and 5:3 ratios of westerly to easterly regime days and PFs with to without ice scattering, reflecting the higher fraction of more intense features contained within the easterly regime days.

Figures $9 a-b$ show a time series of the daily variations in the daily cumulative distribution functions (CDFs) of precipitation feature intensities during the 1998-99 wet season. These time series can be directly compared to Figs. 2, 5, and 6. Daily distributions of the maximum height of the 30-dBZ contour within each PF are shown in Fig. 9a, while Fig. 9b shows the daily variations in minimum $85-\mathrm{GHz}$ PCTs. The dark line indicates the 
TABLE 2. Precipitation feature analysis (south-central AMZ).

\begin{tabular}{|c|c|c|c|c|c|c|c|}
\hline Season & Regime & $\begin{array}{l}\text { Total } \\
\text { PFs }\end{array}$ & $\begin{array}{l}\text { PFs } \\
\text { with } \\
\text { MCS }\end{array}$ & $\begin{array}{l}\text { PFs with ice } \\
\text { scattering }\end{array}$ & $\begin{array}{l}\text { PFs without } \\
\text { ice scattering }\end{array}$ & $\begin{array}{c}\text { PFs with rain } \\
>10^{3} \mathrm{~mm} \mathrm{~h}^{-1} \\
\mathrm{~km}^{2}\end{array}$ & $\begin{array}{l}\text { Percent } \\
\text { of season } \\
\text { in regime }\end{array}$ \\
\hline \multirow[t]{2}{*}{ 1997-98 } & $\mathrm{E}$ & 1276 & 30 & 295 & 981 & 372 & 37.2 \\
\hline & W & 2244 & 38 & 403 & 1841 & 610 & 62.8 \\
\hline \multirow[t]{2}{*}{ 1998-99 } & $\mathrm{E}$ & 1977 & 27 & 471 & 1506 & 561 & 52.1 \\
\hline & $\mathrm{W}$ & 1811 & 34 & 404 & 1407 & 530 & 47.9 \\
\hline \multirow[t]{2}{*}{ 1999-2000 } & $\mathrm{E}$ & 1857 & 39 & 469 & 1388 & 548 & 23.8 \\
\hline & W & 2337 & 38 & 518 & 1819 & 655 & 76.2 \\
\hline \multirow[t]{2}{*}{ Total } & $\mathrm{E}$ & 5110 & 96 & $1235(24.2 \%)$ & $3875(75.8 \%)$ & 1481 & 37.7 \\
\hline & $\mathrm{W}$ & 6392 & 110 & $1325(20.7 \%)$ & $5067(79.3 \%)$ & 1795 & 62.3 \\
\hline
\end{tabular}

median level, while the days containing a red line along the $x$ axis indicate intervals contained within the easterly regime. Despite scatter associated with irregular sampling by the TRMM satellite, it is apparent that the days contained within the easterly regime contain more intense convection as indicated by the most intense radar profiles (i.e., deepest reflectivity cores) and ice scattering signatures (i.e., coldest brightness temperatures). This trend is also evident in the daily time series for the other two seasons (not shown) although to a lesser extent, perhaps due to reductions in the wind anomaly magnitudes. It is clear however, that the daily view of regimes over the south-central AMZ from the TRMM satellite agree qualitatively with the regime transitions noted in the BLDN lightning data (Fig. 6) and other radar studies from TRMM-LBA (e.g., RFHS; CPCR).

To further highlight regime differences, PFs containing at least $10^{3} \mathrm{~mm} \mathrm{~h}^{-1} \mathrm{~km}^{2}$ of volumetric rain were isolated from the entire three wet-season dataset (e.g., Table 2) to compare only systems with significant rainfall between the regimes. Figure 10a shows a CDF of $\mathrm{PF}$ maximum heights of the 20-, 30-, and 40-dBZ echo top. For each echo top height threshold, there is a systematic shift (by as much as $750 \mathrm{~m}$ in some cases)

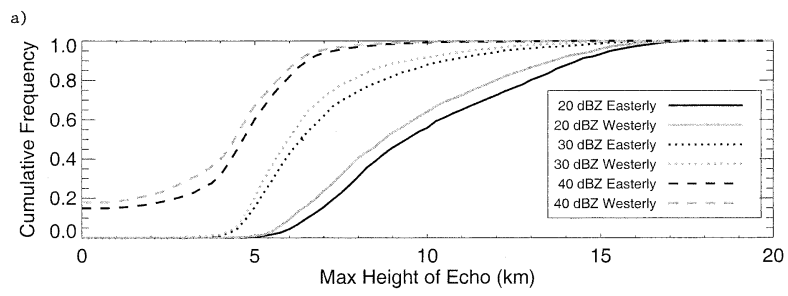

b)

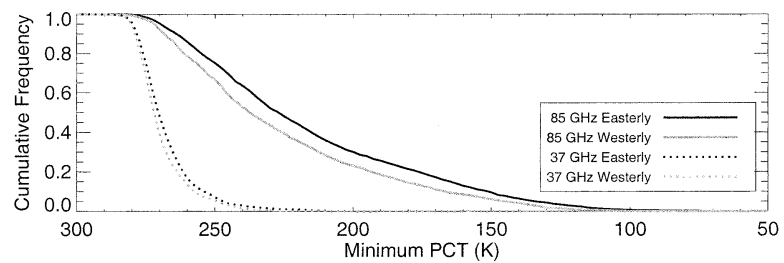

FIG. 10. The 3-yr wet-season CDFs for south-central Amazon PFs containing at least $10^{3} \mathrm{~mm} \mathrm{~h}^{-1} \mathrm{~km}^{-2}$ rain rates partitioned by regime for (a) maximum heights of PR reflectivity at 20-, 30-, and 40-dBZ thresholds; and (b) minimum TMI 85- and 37-GHz PCTs. indicating more intense radar reflectivity profiles in the easterly regime. The differences are fairly uniform at all parts of the distribution. Figure 10b shows a CDF for minimum $85-$ and $37-\mathrm{GHz}$ PCTs for all systems meeting the aforementioned rain volume threshold. Again, both indicators show more intense convection occurring during the easterly regime over the southern AMZ (with the smaller differences at $37 \mathrm{GHz}$ linked to a decreased ice scattering dynamic range at that frequency; Spencer 1986). These systematic differences show that the TRMM satellite identifies regime-dependent differences in convective intensity and vertical structure.

\section{c. Rain-rate distributions}

Case studies of convection observed during TRMMLBA suggest that east-west regime differences in convective structure should also be manifested as changes in the shape of regime rainfall rate distributions (RFHS; CPCR; Carey et al. 2001). Intuitively, larger instantaneous rainfall rates are expected to occur in regimes associated with convection that is more vertically developed (e.g., deep reflectivity cores) and highly electrified. Indeed, utilizing pixel-based rain-rate statistics from the TRMM 2A-25 algorithm (smoothed to account for discretization in measured reflectivity values), the expected behavior in the rain-rate distributions (Fig. 11) is observed for analysis boxes where regime signals in convective structure are most pronounced, for example the Altiplano and south-central AMZ boxes (Figs. 4, 89). Further, the overall shape of the rain-rate distribution is similar to that observed during TRMM-LBA (Carey et al. 2001).

Though slight differences in rain rates $\leq 10 \mathrm{~mm} \mathrm{~h}^{-1}$ do exist between the regimes in Fig. 11 (lower rainfall rates are not emphasized on Fig. 11), by far, the largest relative differences in the $2 \mathrm{~A}-25$ rainfall rate distribution appear at the relatively small percentage of rain rates exceeding $10 \mathrm{~mm} \mathrm{~h}^{-1}$. This implies that regime differences in rainfall are dominated by differences in convective precipitation as opposed to stratiform (e.g., Austin and Houze 1972; Steiner et al. 1995; Atlas et al. 1999; Belcher 2000). It is important to note that though 
TRMM 2A-25 Rain Rate Distributions (2 km) South Central AMZ and Altiplano East vs. West (97/98-99/00)

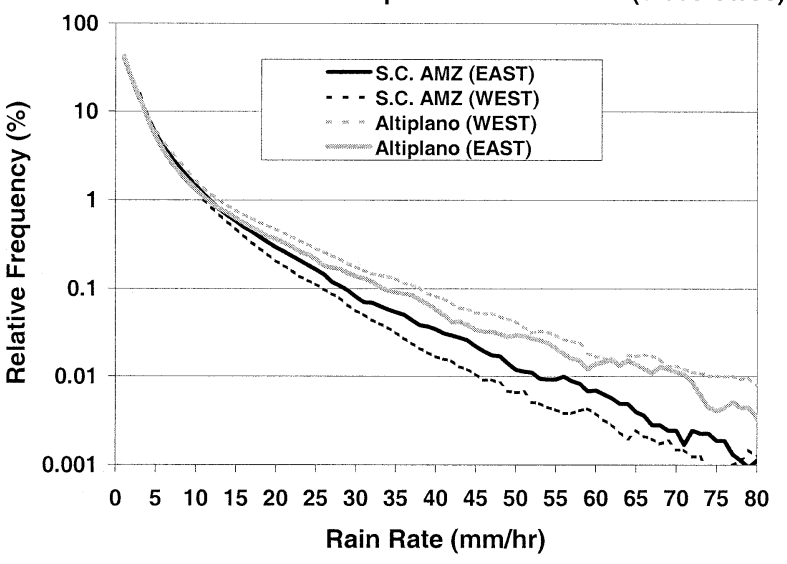

FIG. 11. TRMM 2A-25 smoothed rainfall rate distributions for the south-central Amazon and Altiplano regions of South America. Solid (dashed) lines indicate easterly (westerly) regimes.

rain rates exceeding $10 \mathrm{~mm} \mathrm{~h}^{-1}$ amount to $\leq 1 \%$ of the total sample analyzed in this study (Fig. 11), several studies of tropical rainfall have noted that greater than $50 \%$ of accumulated rainfall occurs as the result of rainfall classified as "convective" (e.g., Gamache and Houze 1983; Simpson et al. 1993; Steiner et al. 1995; Cifelli and Rutledge 1998; Rickenbach and Rutledge 1998), and/or falling at rates in excess of $10 \mathrm{~mm} \mathrm{~h}^{-1}$ (e.g., Rosenfeld et al. 1995). Indeed, $>50 \%$ of the total rain volume measured in the SWAMZ during TRMMLBA occurred at rain rates in excess of $10 \mathrm{~mm} \mathrm{~h}^{-1}$, but these rain rates made up less than $5 \%$ of the total rainrate distribution by occurrence (L. D. Carey 2001, personal communication).

Differences in convective vertical structure and lightning flash density between the east and west regimes suggest that convective precipitation processes in the two regimes may also be different. For example, regimes associated with larger rainfall rates occurred with more vertically developed (e.g., Fig. 8a) and more highly electrified convection, implying a greater contribution to rainfall via mixed-phase ice processes. These are important points because from a diabatic heating perspective, differences in diabatic heating between the two regimes are likely to be dominated by regime differences in the convective heating profile (e.g., Houze 1989).

While we have not rigorously examined accumulated rainfall for the regimes in each area, results from TRMM-LBA (and also those of Fig. 5) suggest that the area mean daily accumulated rainfall ${ }^{5}$ produced in each regime is similar (Carey et al. 2001; RFHS). Hence regimes associated with more intense convection and larger instantaneous rainfall rates are also likely to be associated in a relative sense with either smaller (in an

\footnotetext{
${ }^{5}$ Here we explicitly differentiate between daily means and longer accumulations such as monthly or seasonal.
}

area coverage) or less frequently occurring convective systems. Observations presented in RFHS suggest that the former is the case, at least in the SWAMZ. For example, during westerly regimes over the SWAMZ RFHS reported that convective systems exhibited rainfall rates that were $28 \%$ weaker in intensity (due to more stratiform precipitation) than those observed in easterly regimes, but the westerly regime systems covered $40 \%$ more area. If the mean daily accumulated rainfall is approximately the same between the regimes, then differences in the rainfall rate distribution (Fig. 11) coupled with the differences observed in convective structure between the regimes suggest that (i) a larger amount of latent heating per unit mass of cloud occurs in regimes with more vertically developed convection, and (ii) the vertical distribution of latent heating and mass flux in the two regimes are likely to be different (Houze 1989; CPCR).

\section{Summary and conclusions}

Analysis of TRMM datasets (precipitation radar, lightning imaging sensor, and microwave radiometer), ground-based lightning location network, and NCEPNCAR reanalysis data reveal a systematic intraseasonal (submonthly) variability in convective vertical structure as a persistent feature of the convection occurring over portions of the Amazon basin and central and southern South America. Consistent with observations collected during TRMM-LBA, this variability can be decomposed into two regimes denoted as "easterly" or "westerly," based on the sign of seasonal low- to midlevel (850-700 mb) zonal wind anomalies in the southwestern Amazon. Regime composites of the wind field at 850 and $700 \mathrm{mb}$ suggest that changes in the low-level flow regime (from easterly to westerly or visa versa) occur not only over the southwestern Amazon, but across a significant part of central and southern South America.

For example, in the easterly regime composite a northwest-southeast-oriented axis of anticyclonic flow extends from the South Atlantic high into the extreme southwestern Amazon. This feature is associated with a strong east-northeast flow across the Amazon that originates along the South American coast and penetrates all the way inland to the foothills of the northern Andes. During westerly regimes the axis of anticyclonic flow is shifted north to the central Amazon and a northwesterly jet develops along the foothills of the northern Andes and over southwestern Amazon. The resultant change in the low-level flow provides a moist influx of air from the Amazon into portions of subtropical South America, and an enhanced confluence of low-level flow into the South Atlantic convergence zone. Areas between the equator and $15^{\circ} \mathrm{S}$ that are not located in the southwestern Amazon, experience either a marked weakening in easterly trade flow or a weak northwesterly flow.

The continental-scale pattern of the vector difference 
in low-level wind between the two regimes is similar in many respects to the pattern of low-level wind anomalies associated with the influence of midlatitude frontal systems and baroclinic waves on Amazonian convection (e.g., Garreaud and Wallace 1998; Liebmann et al. 1999; RFHS). Interestingly, the regime wind vector difference pattern also strongly resembles the "South American monsoon" low-level wind anomaly pattern presented in Zhou and Lau (1998). Hence it seems conceivable that the westerly and easterly regimes examined herein, are related in some way to either, or both, the intrusion of midlatitude frontal systems/disturbances into the subtropics and Tropics and/or submonthly modulation of the South American "monsoon" (perhaps neither process being mutually exclusive).

Marked changes in the vertical structure of deep convection were found to accompany regime changes in the low-level flow. These regime changes in the convective structure were manifested in both three-dimensional PR reflectivity histograms (based on counting pixels), and in individual precipitation feature statistics (cumulative distribution functions) computed from both PR and TMI data. The regime changes were also well manifested in other parameters related to convective structure such as rainfall rate distributions, the diurnal cycle of lightning (which parallels that of precipitation; RFHS), and time series of cloud-to-ground lightning flash counts. When combined, the statistics reveal that during easterly (westerly) regimes, convection over the southern Amazon and Mato Grosso tends to exhibit more (less) robust vertical development as evinced by greater (lesser) vertical extension of precipitation cores possessing reflectivities in excess of $30 \mathrm{dBZ}$, colder (warmer) $85-\mathrm{GHz}$ brightness temperatures, larger (smaller) convective rainfall rates, and relatively more (less) lightning activity. Interestingly, but consistent with the regime-relative changes in the wind field, over the Altiplano region, southern Brazil, and along the coastline in central and southern South America, the situation was reversed. Westerly regimes were associated with more robust vertical development, larger lightning flash rates, and larger rainfall rates (easterly regimes in these areas exhibited the opposite tendencies). In the central and west-central Amazon (e.g., north of $5^{\circ} \mathrm{S}$ ), very little change was observed to occur with the changes in the low-level wind regime.

Radar observations from the southwestern AMZ during TRMM-LBA suggest that there was relatively little difference in the daily mean rainfall totals between easterly and westerly regimes (Carey et al. 2001). Further, both TRMM-LBA and TRMM satellite observations suggest marked differences in the rainfall rate distributions, with the easterly (westerly) regime in the AMZ (Altiplano/southern Brazil) being associated with a broader rain-rate distribution and attendant heavier instantaneous rainfall rates. If similar daily accumulations of rainfall but dissimilar rain-rate distributions are typical of all the locations as a function of regime, then in the mean, regimes associated with stronger vertical development, more lightning activity, and larger instantaneous rainfall rates must be associated with a more "concentrated" daily latent heat release (i.e., greater amount of latent heat release per unit of cloud volume). This is consistent with observations from TRMM-LBA where it was noted that a greater areal coverage of rainfall occurs during westerly regimes, but the rain falls at a correspondingly lower rate and in association with more weakly developed convection (e.g., RFHS).

Thus far, two mechanisms have been proposed to explain the observed changes in overall convective structure and lightning frequency between the two regimes (e.g., WIL). These mechanisms are tied to either thermodynamics (changes in CAPE and CIN that modify the energetics of the cloud ensemble), or aerosol loading (e.g., changes in $\mathrm{CCN}$ concentration that modify cloud ensemble microphysical structure). Dynamical explanations (changes in shear or convective organization, etc.) have yet to be explored. Regardless of which mechanism plays a more important role in manifesting regime characteristics such as a change in convective vertical structure or rainfall, the changes in regime are systematic and observable.

From a TRMM physical validation perspective, these results, when compared to those of TRMM-LBA suggest that the TRMM satellite is capturing a significant portion of the intraseasonal variability in convective structure and rainfall over the Amazon. In turn, remote sensing of changes in the diurnal cycle, vertical structure, and intensity of rainfall as a function of intraseasonal regime have important implications for precipitation estimation and thus quantification of the hydrologic cycle on a regional basis in South America. More importantly, the results herein suggest that, while not perfect, changes in cloud-ensemble properties such as vertical precipitation structure can be crudely inferred for regions of the Amazon basin and vicinity utilizing the 850-mb zonal wind anomaly (a "resolved" variable) and/or tendencies in other parameters such as the lightning flash count (an easily measured, countable quantity). With future research it may be possible to refine the definition of the large-scale regimes in the Amazon and to better establish the statistical properties associated with the convection therein. The resultant outcome could have important implications for cumulus parameterization and representation of diabatic heating profiles in large-scale numerical models, latent heat retrievals, and rainfall estimation over the Amazon and other regions of South America.

Acknowledgments. This research was supported by Dr. Ramesh Kakar of the NASA TRMM program under Grants NAG5-9642 (Colorado State University), NCC5288 (CEAS), NAG5-9717 (University of Utah), and by NASA Headquarters and the NASA EOS Program under Task Numbers 622-29-40 and 229-21-46, respectively (NASA MSFC). We would like to acknowledge valuable 
discussions with Dr. Lawrence D. Carey, Dr. Leila Carvalho, Dr. Tom Rickenbach, Dr. Jeff Halverson, Prof. Ed Zipser, Dr. Earle Williams, Prof. Maria Silva Dias, Dr. Carlos Morales, and Dr. Rong Fu. Dr. Jeff Bailey assisted with processing of the BLDN lightning data.

\section{REFERENCES}

Atlas, D., C. W. Ulbrich, F. D. Marks Jr., E. Amitai, and C. R. Williams, 1999: Systematic variation of drop-size and radar-rainfall relations. J. Geophys. Res., 104, 6155-6169.

Austin, P. M., and R. A. Houze Jr., 1972: Analysis of the structure of precipitation patterns in New England. J. Appl. Meteor., 11, 926-935.

Belcher, L., 2000: Classification of tropical precipitation regimes: A comparative analysis of disdrometer, profiler, and multi-parameter radar measurements. M.S. thesis, Dept. of Atmospheric Science, Colorado State University, $105 \mathrm{pp}$.

Blakeslee, R. J., J. C. Bailey, W. J. Koshak, and O. Pinto, 1999: The Rondonia lightning detection network: Network description, science objectives, data processing/archival methodology, and first results. Abstracts, American Geophysical Union 1999 Fall Meeting, San Francisco, CA, Amer. Geophys. Union, A31B-12.

Boccippio, D. J., S. J. Goodman, and S. Heckman, 2000: Regional differences in tropical lightning distributions. J. Appl. Meteor., 39, 2231-2248.

Carey, L. D., R. Cifelli, W. A. Petersen, and S. A. Rutledge, 2001: Characteristics of Amazonian rain measured during TRMMLBA. Preprints, 30th International Conf. on Radar Meteorology, Munich, Germany, Amer. Meteor. Soc., 682-684.

Cartwright, T. J., and P. S. Ray, 1999: Radar-derived estimates of latent heating in the subtropics. Mon. Wea. Rev., 127, 726-742.

Carvalho, L. M. V., C. Jones, and M. A. F. Silva Dias, 2002: Intraseasonal large-scale circulations and mesoscale convective activity in tropical South America during the TRMM-LBA campaign. J. Geophys. Res., in press.

Cifelli, R., and S. A. Rutledge, 1998: Vertical motion, diabatic heating, and rainfall characteristics in north Australia convective systems. Quart. J. Roy. Meteor. Soc., 124, 1133-1162.

- W. A. Petersen, L. D. Carey, and S. A. Rutledge, 2002: Radar observations of the kinematic, microphysical, and precipitation characteristics of two MCSs in TRMM-LBA. J. Geophys. Res., in press.

Cohen, J. C. P., M. A. F. Silva Dias, and C. A. Nobre, 1995: Environmental conditions associated with Amazonian squall lines: A case study. Mon. Wea. Rev., 123, 3163-3174.

Fu, R., B. Zhu, and R. E. Dickinson, 1999: How do atmosphere and land surface influence seasonal changes of convection in the tropical Amazon? J. Climate, 12, 1306-1321.

Gamache, J. F., and R. A. Houze Jr., 1983: Water budget of a mesoscale convection system. J. Atmos. Sci., 40, 1835-1850.

Garreaud, R. D., and J. M. Wallace, 1998: Summertime incursions of midlatitude air into subtropical and tropical South America. Mon. Wea. Rev., 126, 2713-2733.

Garstang, M., H. Massie Jr., J. Halverson, S. Greco, and J. Scala, 1994: Amazon coastal squall lines. Part I: Structure and kinematics. Mon. Wea. Rev., 122, 608-622.

Halverson, J. B., T. Rickenbach, B. Roy, and H. Pierce, 2002: Environmental characteristics of convective systems during TRMM-LBA. Mon. Wea. Rev., 130, 1493-1509.

Holland, G. J., 1986: Interannual variability of the Australian summer monsoon at Darwin: 1952-82. Mon. Wea. Rev., 114, 594-604.

Houze, R. A., Jr., 1989: Observed structure of mesoscale convective systems and implications for large-scale heating. Quart. J. Roy. Meteor. Soc., 115, 425-461. 1993: Cloud Dynamics. Academic Press, 573 pp.

Huffman, G. J., and Coauthors, 1997: The Global Precipitation Climatology Project (GPCP) combined precipitation dataset. Bull. Amer. Meteor. Soc., 78, 5-20.
Iguchi, T., and R. Meneghini, 1994: Intercomparison of single-frequency methods for retrieving a vertical rain profile from airborne or spaceborne radar data. J. Atmos. Oceanic Technol., 11, $1507-1517$

, T. Kozu, R. Meneghini, J. Awaka, and K. Okamoto, 2000: Rain-profiling algorithm for the TRMM precipitation radar. $J$. Appl. Meteor., 39, 2038-2052.

Kalnay, E., and Coauthors, 1996: The NCEP/NCAR 40-Year Reanalysis Project. Bull. Amer. Meteor. Soc., 77, 437-471.

Kummerow, C., and L. Giglio, 1994: A passive microwave technique for estimating rainfall and vertical structure information from space. Part I: Algorithm description. J. Appl. Meteor., 33, 3-18.

Lenters, J. D., and K. H. Cook, 1999: Summertime precipitation variability over South America: Role of the large-scale circulation. Mon. Wea. Rev., 127, 409-431.

Liebmann, B., G. N. Kiladis, J. A. Marengo, T. Ambrizzi, and J. D. Glick, 1999: Submonthly convective variability over South American and the South Atlantic Convergence Zone. J. Climate, 12, 1877-1891

Marengo, J. A., B. L. Liebmann, V. E. Kousky, N. P. Filizola, and I. C. Wainer, 2001: Onset and end of the rainy season in the Brazilian Amazon Basin. J. Climate, 14, 833-852.

Meneghini, R., T. Iguchi, T. Kozu, T. Kwanishi, H. Kuroiwa, K. Okamoto, and D. Atlas, 1999: The TRMM precipitation radar: Opportunities and challenges. Preprints, 29th International Conf. on Radar Meteorology, Montreal, Quebec, Canada, Amer. Meteor. Soc., 621-624.

Mohr, K. I., and E. J. Zipser, 1996: Mesoscale convective systems defined by their $85-\mathrm{GHz}$ ice scattering signature: Size and intensity comparison over tropical oceans and continents. Mon. Wea. Rev., 124, 2417-2437.

_ _ J. S. Famiglietti, and E. J. Zipser, 1999: The contribution to tropical rainfall with respect to convective system type, size and intensity estimated from $85-\mathrm{GHz}$ ice-scattering signature. $J$. Appl. Meteor., 38, 596-606.

Nesbitt, S. W., E. J. Zipser, and D. J. Cecil, 2000: A census of precipitation features in the tropics using TRMM: Radar, ice scattering and lightning observations. J. Climate, 13, 4087-4106.

Nogues-Paegle, J., and K. C. Mo, 1997: Alternating wet and dry conditions over South America during summer. Mon. Wea. Rev., 125, 279-291.

Petersen, W. A., and S. A. Rutledge, 2001: Regional variability in tropical convection: Observations from TRMM. J. Climate, 14, 3566-3586.

_ _ _ , and R. E. Orville, 1996: Cloud-to-ground lightning observations from TOGA COARE: Selected results and lightning location algorithms. Mon. Wea. Rev., 124, 602-620.

Rickenbach, T. M., and S. A. Rutledge, 1998: Convection in TOGA COARE: Horizontal scale, morphology and rainfall production. J. Atmos. Sci., 55, 2715-2729.

_ R. N. Ferreira, J. Halverson, and M. A. F. Silva Dias, 2002: Mesoscale properties of convection in western Amazonia in the context of large-scale wind regimes. J. Geophys. Res., in press.

Rosenfeld, D., and M. Lensky, 1998: Satellite-based insights into precipitation formation processes in continental and maritime convective clouds. Bull. Amer. Meteor. Soc., 79, 2457-2476.

_ E. Amitai, and D. B. Wolff, 1995: Classification of rain regimes by the three-dimensional properties of reflectivity fields. J. Appl. Meteor., 34, 198-211.

Rutledge, S. A., E. R. Williams, and T. D. Keenan, 1992: The Down Under Doppler and Electricity Experiment (DUNDEE): Overview and preliminary results. Bull. Amer. Meteor. Soc., 73, 316.

Silva Dias, M. A. F., and R. N. Ferreira, 1992: Application of the linear spectral model to the study of Amazonian squall lines during GTE/ABLE 2B. J. Geophys. Res., 97, 20 405-20 219.

_ - and Coauthors, 2002: Clouds and rain processes in a biosphere atmosphere interaction context in the Amazon region. J. Geophys. Res., in press.

Simpson, J., T. D. Keenan, B. Ferrier, R. H. Simpson, and G. J. 
Holland, 1993: Cumulus mergers in the Maritime Continent Region. Meteor. Atmos. Phys., 51, 73-99.

Spencer, R. W., 1986: A satellite passive $37 \mathrm{GHz}$ scattering based method for measuring oceanic rain rates. J. Climate Appl. Meteor., 25, 754-766.

— H. M. Goodman, and R. E. Hood, 1989: Precipitation retrieval over land and ocean with the SSM/I: Identification and characteristics of the scattering signal. J. Atmos. Oceanic Technol., 6, 254-273.

Steiner, M., R. A. Houze Jr., and S. E. Yuter, 1995: Climatological characterization of three-dimensional storm structure from operational radar and rain gauge data. J. Appl. Meteor., 34, 19782007.

Sun, W.-Y., and I. Orlanski, 1981: Large mesoscale convection and sea breeze circulation. Part I: Linear stability analysis. J. Atmos. Sci., 38, 1675-1993.

Tao, W.-K., J. Simpson, S. Lang, M. McCumber, R. Adler, and R. Penc, 1990: An algorithm to estimate the heating budget from vertical hydrometeor profiles. J. Appl. Meteor., 29, 1232-1244.
— and testing of the heating retrieval algorithm for TRMM. $J$. Meteor. Soc. Japan, 71, 685-700.

Toracinta, R. E., and E. J. Zipser, 2001: Lightning and SSM/I-IceScattering Mesoscale Convective Systems in the global Tropics. J. Appl. Meteor., 40, 983-1002.

Williams, E. R., S. A. Rutledge, S. C. Geotis, N. Renno, E. Rasmussen, and T. Rickenbach, 1992: A radar and electrical study of tropical hot towers. J. Atmos. Sci., 49, 1386-1395.

_ , and Coauthors, 2002: The green ocean over the Amazon: Implications for cloud-electrification. J. Geophys. Res., in press.

Yang, S., and E. A. Smith, 1999: Four-dimensional structure of monthly latent heating derived from SSM/I satellite measurements. J. Climate, 12, 1016-1037.

Zhou, J., and K.-M. Lau, 1998: Does a monsoon exist over South America? J. Climate, 11, 1020-1040.

Zipser, E. J., and K. R. Lutz, 1994: The vertical profile of radar reflectivity of convective cells: A strong indicator of storm intensity and lightning probability? Mon. Wea. Rev., 122, 17511759. 